\title{
Wear Comparison of a Plain Toothbrush versus Eleven Commercial Toothbrushes
}

\author{
Fansiwala N*, Phan B, Tran D, Dunn K, Kang, Y, Cimmino J, Bairos T and \\ Kugel G \\ Tufts School of Dental Medicine, USA
}

*Corresponding author: Natasha Fansiwala BS, Tufts School of Dental Medicine, One Kneeland Street Boston MA 02111, USA, Tel: 518-879-9621; Email: natasha.fansiwala@tufts. edu

\section{Research Article \\ Volume 6 Issue 4}

Received Date: September 18, 2021

Published Date: October 07, 2021

DOI: $10.23880 /$ oajds-16000311

\section{Abstract}

Objective: To compare the wear of the Sound Feelings SOFT Plain Toothbrush 47 tuft (flat bristles) versus eleven manual toothbrushes.

Methods: Twelve brand-new manual toothbrushes ( $\mathrm{n}=35$ in each group) were used for comparison. Each toothbrush was run on a toothbrushing simulator with a brushing force of $2 \mathrm{~N}$ for approximately 2 hours to simulate 1 month of toothbrushing (9,333 strokes@ @ $5^{\circ}$ lingual of posterior teeth, 9,333 strokes on the top surface, and 9,333 strokes @ 45 buccal of posterior teeth), using the Bass technique on a quadrant typodont. Wear was measured by wear index and wear rating. The Wear index measures the degree of bristle splaying whereby the bristles spread apart and take on a permanent curvature. Wear rating is a subjective rating scale consisting of a series of four numbers increasing from zero to three. The Olympus SZX16 microscope was used to measure the wear rating then was inputted into a formula and averaged. The subjective wear seen as bristle splay/ curling was also measured and recorded. Comparison of the wear index and wear rating between each manual toothbrush was conducted using the Mann-Whitney test.

Results: Wear index and wear rating for all toothbrushes ranged from 0.03 to 0.34 and from 0.57 to 2.06 , respectively. There was a significant difference in the wear index between each toothbrush and the Sound Feelings SOFT Plain toothbrush. The difference in the wear rating was significant between the Sound Feelings SOFT Plain toothbrush and all other toothbrushes other than the Reach Advanced Design Soft toothbrush.

Conclusion: The Sound Feelings SOFT Plain Toothbrush had the lowest wear rating and index among all the manual toothbrushes tested.

Keywords: Toothbrush; Wear Index; Wear Rating; Toothbrushing Simulator

\section{Introduction}

As more research has been done to connect the oral cavity to the rest of the body, more people have begun to take better care of their oral health. Poor oral hygiene can cause tooth decay and gum disease, which can be linked to cancer, diabetes and heart disease [1]. Caries are caused by bacteria plaque that reside on the tooth surface and produce acid from feeding on sugars that then demineralize the enamel [2]. Periodontal disease, on the other hand, is due to poor 
oral hygiene which causes inflammation and pockets of bacteria that cause infection within the gingiva [1]. Many strategies are used to prevent both of these conditions, such as fluoridation, flossing, a proper diet, regular prophylaxis treatments from the hygienist, visits to the dentist and brushing. It is recommended that everyone should floss at least once a day and brush their teeth at least twice a day [3].

There are two types of toothbrushes that are available, mechanical and electric. Many people prefer mechanical toothbrushes, since it is what they are used to, they feel that it gives them a better clean, it allows them to have better control of the toothbrush and it does not give their gingiva the "tickling" feeling that the electric brush does. A lot of the elderly population prefer the mechanical brush due to these reasons [4].

Mechanical brushes are recommended to be replaced every 3 to 4 months. This is due to the wear of the bristles not allowing there to be an efficient removal of plaque. The bristles will look matted and curled when this occurs [5]. With more extreme wear of the toothbrush, the less plaque the patient is able to remove efficiently. This causes the worn-out toothbrushes to be less effective and be more likely to cause caries and periodontal disease [6].

There are many factors that contribute to the breakdown of toothbrush bristles, which vary from patient to patient. The more force that is applied on the toothbrush against the teeth while brushing, the quicker the toothbrush will wear. The duration of brushing also plays a role with the greater the amount of brushing time causing more wear. The socioeconomic status and the brushing pattern/technique of the patient also plays a role in toothbrush wear [7].

Brushes can vary in the length, the material, the positioning and the amount of the bristles. The toothbrushes in this study were chosen taking these considerations into account, in order to test all the different types of brushes on the market. Brush width and maximum bristle length are the most reliable ways to measure the wear of toothbrushes. The longevity of the brushes should not be impacted by their different properties. Preliminary research showed that the flat cut (compared to modern multilevel bristle toothbrushes) helped prevent wear because the compact same-length bristles tend to support each other under stress and prevent splaying [5]. The Sound Feelings SOFT Plain Toothbrush 47 tuft is an old-fashioned style toothbrush with flat bristles. There has been no published paper comparing its wear with other commercial toothbrushes. This study aimed to compare the wear of the Sound Feelings SOFT Plain Toothbrush 47 tuft (flat bristles) versus eleven manual toothbrushes. It is hypothesized that there is no difference in the wear between the Sound Feelings SOFT Plain Toothbrush 47 tuft (flat bristles) and the eleven commercial toothbrushes.

\section{Materials and Methods}

Twelve groups of brand-new manual toothbrushes ( $\mathrm{n}=$ 35 in each group) were used for the comparison. The groups were as follows:

- Group 1: The Sound Feelings SOFT Plain Toothbrush 47 tuft (flat bristles) (Plain Toothbrush)

- Group 2: Colgate ZigZag Black Soft Bristle Toothbrush (zig zag bristles) (Colgate-Palmolive Company)

- Group 3: Oral-B 35 Soft Bristles 3D Vivid Toothbrush (polishing cup bristles) (Oral B®)

- Group 4: Oral-B 40 Soft Bristles Complete Deep Clean Toothbrush (multilevel bristles) (Oral Bß)

- Group 5: RADIUS Original Right Hand Toothbrush, Soft Bristles (flat bristles) (RADIUS)

- Group 6: Colgate Extra Clean Toothbrush (circular power bristles) (Colgate-Palmolive Company)

- Group 7: Oral-B Pro-Health Clinical Pro-Flex Toothbrush with Flexing Sides, 40M (multilevel/Pro-Flex bristles) (Oral $\mathrm{B} \AA$ )

- Group 8: Xlent Dental Activated Charcoal Bristle Toothbrush (Tapered charcoal-infused polyester bristles) (Xlent Dental Products Inc.)

- Group 9: Nimbus® Microfine ${ }^{\circledR}$ Toothbrush REGULAR size (multilevel and multi-tufted/varying stiffness bristles) (Nimbus $\AA$ Microfine $\AA$ )

- Group 10: GUM Technique Deep Clean Toothbrush - 525 Soft Compact (multilevel/fine-tapered bristles) (Sunstar Americas, Inc.,)

- Group 11: Reach Advanced Design Soft (bi-level bristles) (REACH®)

- Group 12: Colgate 360 Optic White Platinum soft (stain erasing cups with spiral bristles) (Colgate-Palmolive Company)

Each toothbrush was placed into a toothbrushing simulator and the system was programmed to automatically brush a quadrant typodont, Figure 1, (Kilgore International, Inc). The brush heads were cut to secure them into place. Based on brushing twice a day for 2 minutes, the system brushed the quadrant typodont for approximately 2 hours 1 minute and 30 seconds to simulate 4 weeks (1 month) of toothbrushing. The simulator was set to achieve a brushing force of $2 \mathrm{~N}$ and 28,000 single strokes to replicate 4 weeks of brushing. 


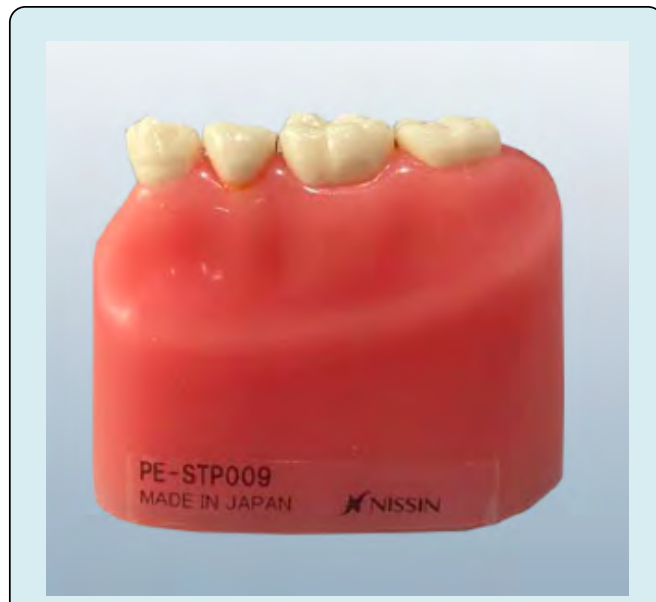

Figure 1: Quadrant typodont.

The simulator incorporated multiple angles and movements of brushing, to emulate the way people brush according to the Bass Method of brushing. This included top surfaces, side surfaces and also holding the brush at $45^{\circ}$ angles, which is often the method recommended by dentists to make sure the bristles clean the sulcus. The steps for the Bass Method are as follows: place the toothbrush parallel to the teeth with the bristles toward the gums, tilt the brush to a $45^{\circ}$ angle and move the bristles slightly under the gumline, with firm but gentle pressure. While maintaining the bristles under the gum tissue, wiggle or vibrate the brush back and forth. Brush the outer surface of the teeth and then continue the same technique on the tongue side and chewing surface of the molar teeth (Figure 2).

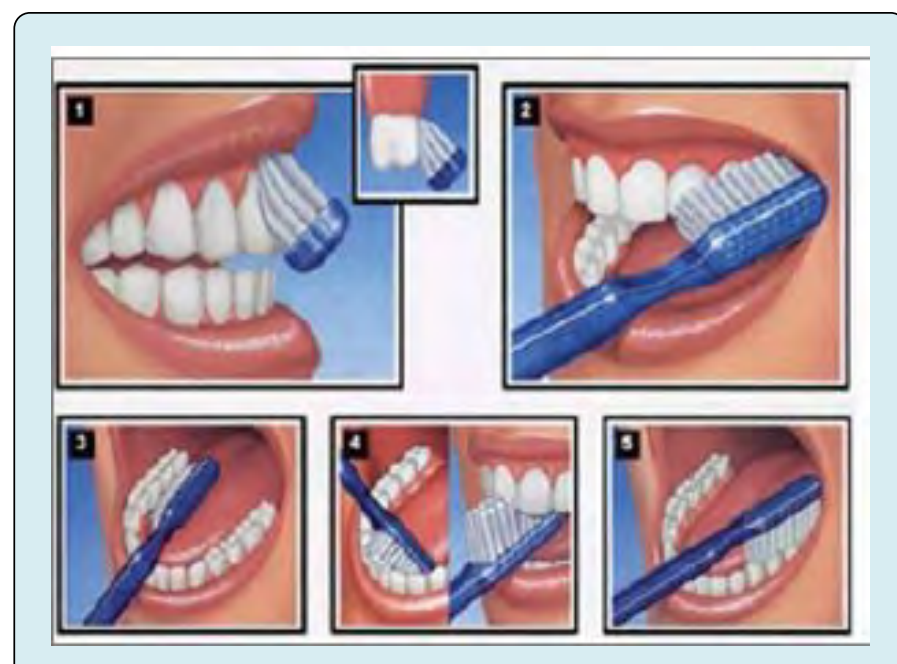

Figure 2: The Bass method of brushing [8].

Each brush was run at 3 different angles to mimic the Bass method of brushing with 9333 strokes at $45^{\circ}$ to the lingual of posterior teeth, 9333 strokes on the top surface and 9333 strokes at $45^{\circ}$ to the buccal of posterior teeth. Multiple typodonts were used and each brush was rotated to a different typodont after 3111 strokes. This was done 3 times for each brushing angle to ensure consistency.

Wear index and wear rating suggested by Rawls, et al. [5] was used to measure the wear of each toothbrush after approximately 2 hours 1 minute and 30 seconds of brushing. The Wear index measured the degree of bristle splay whereby the bristles were spread apart and took on a permanent curvature.

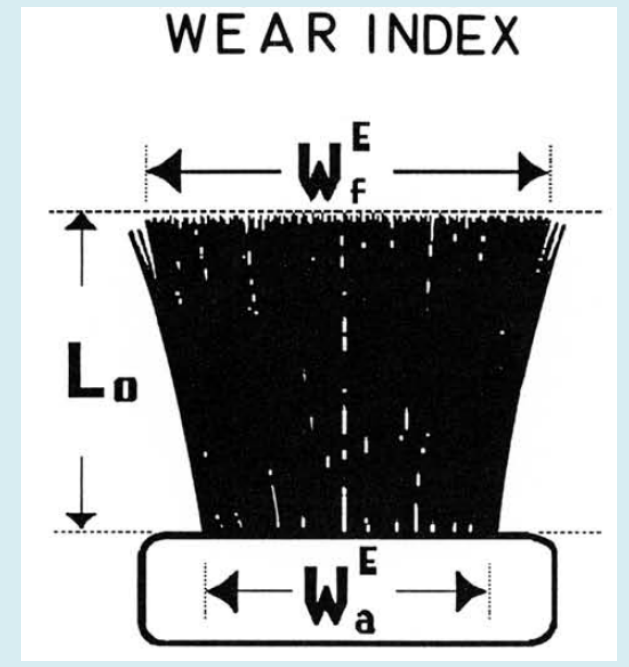

Figure 3: Method used to determine wear index (WI) from a silhouette [5].

We measured the toothbrushes in silhouette from both the side and end-on views, using a digital microscope, and averaged the results. The formula for calculating the Wear Index was as follows:

$$
\mathrm{WI}=\frac{\mathrm{W}_{\mathrm{t}}^{\mathrm{s}}-\mathrm{W}_{\mathrm{a}}^{\mathrm{s}}-\mathrm{W}_{\mathrm{f}}^{\mathrm{E}}-\mathrm{W}_{\mathrm{a}}^{\mathrm{E}}}{2 \mathrm{~L}_{0}}
$$

$\mathrm{W}_{\mathrm{f}}^{\mathrm{S}}=$ Viewed from the side, the width of the brush measured at free ends of the bristles (which was done first).

$\mathrm{W}_{\mathrm{a}}^{\mathrm{S}}=$ The measurement of the width at the anchored ends of the bristles (was measured second then subtracted from $\mathrm{W}_{\mathrm{f}}^{\mathrm{S}}$, giving the amount increased in width at the brushing surface)

$\mathrm{W}_{\mathrm{f}}^{\mathrm{E}}=$ End-on view measurement of the width of the brush at the free ends of the bristles (was done third).

$\mathrm{W}_{\mathrm{a}}^{\mathrm{E}}=$ End-on view measurement of the anchored ends of the bristles (was measured fourth and subtracted from $\mathrm{W}_{\mathrm{f}}^{\mathrm{E}}$ )

$\mathrm{W}=$ maximum brush width measured along one side, $\mathrm{W}^{\mathrm{s}}$, and one end, $\mathrm{W}^{\mathrm{E}}$, of the brush head, and at the anchored (zero splay) ends, $\mathrm{W}_{\mathrm{a}^{\prime}}$ and the free (splayed) ends, $\mathrm{W}_{\mathrm{f}}$, of the bristles. 
$\mathrm{L}_{\mathrm{o}}=$ maximum brush trim height before the brush was used, or the length of the highest standing bristle as long as a vertical bristle remains. It was measured from the side view, the length of the base to the tip of the longest bristle [5].

Wear rating assessment was conducted on all toothbrushes. It was a subjective rating scale consisting of a series of four numbers increasing from zero to three. Scores of the Wear rating can be seen in Table 1 and Figure 4. The observers independently recorded the scores for each of the toothbrushes in a chart.

\begin{tabular}{|c|c|c|}
\hline Scale Rating & Appearance of the Brush & Probable Wear* \\
\hline 0 & One cannot be sure if the brush has been used or not. & None to Slight (0-25\%) \\
\hline 1 & The bristles appear to be spread apart within many of the tufts. & Low (26-49\%) \\
\hline 2 & $\begin{array}{c}\text { All tufts are spread apart, many overlap other tufts, and many bristles are curled } \\
\text { and/or matted. }\end{array}$ & Medium (50-75\%) \\
\hline 3 & $\begin{array}{c}\text { Most tufts overlap and are matted together. Many curled and bent bristles can be } \\
\text { seen. }\end{array}$ & Heavy (76-100\%) \\
\hline
\end{tabular}

*Probable wear=percentage of wear present according to the brush's appearance; eg., if it appears 50 to $75 \&$ worn, then assign a rating of 2

Table 1: Numerical explanation of subjective toothbrush wear rating scale [5].

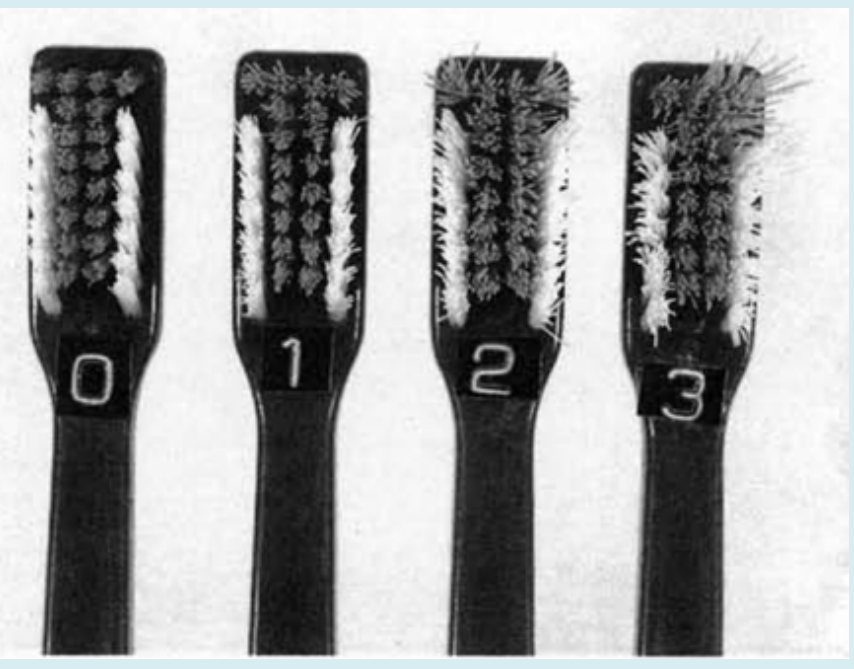

Figure 4: Visual comparison of the subjective wear rating scale 5: $0=$ None, $1=$ Low, $2=$ medium, 3= High [5].

Two independent dental students, who were calibrated prior, took part in this pilot study to observe the toothbrush wear. Observations of the toothbrushes were done within 12 hours of the brushing simulation being run and were observed in a well-lit area under overhead lighting.

Comparison of the wear index and wear rating between the Sound Feelings SOFT Plain Toothbrush and each commercial toothbrush was conducted using the two-sample independent $t$ test to calculate mean and standard deviation and Mann-Whitney test to calculate P-value. The ShapiroWilk test was performed to assess normality. All p-values less than 0.05 were considered statistically significant. The statistical software Stata 15 was used for analysis.

\section{Results}

Wear index and wear rating ranged from 0.03 to 0.34 and from 0.57 to 2.06, respectively (Tables $2 \& 3$ ). There was a significant difference in the wear index between each group and the Sound Feelings SOFT Plain Toothbrush (Table 2). The difference in the wear rating was significant between the Sound Feelings SOFT Plain Toothbrush and all groups other than 11 (Table 3). 


\begin{tabular}{|c|c|c|c|}
\hline Toothbrush Name & Group & Wear Index ${ }^{1}$ & P-value ${ }^{2}$ \\
\hline Sound Feelings SOFT Plain Toothbrush & 1 & $0.03 \pm 0.08$ & \\
\hline Colgate ZigZag Black Soft Bristle Toothbrush & 2 & $0.10 \pm 0.04$ & $<0.001$ \\
\hline Oral-B 35 Soft Bristles 3D Vivid Toothbrush & 3 & $0.20 \pm 0.11$ & $<0.001$ \\
\hline Oral-B 40 Soft Bristles Complete Deep Clean Toothbrush & 4 & $0.34 \pm 0.11$ & $<0.001$ \\
\hline RADIUS Original Right Hand Toothbrush, Soft Bristles & 5 & $0.06 \pm 0.14$ & 0.013 \\
\hline Colgate Extra Clean Toothbrush & 6 & $0.22 \pm 0.08$ & $<0.001$ \\
\hline Oral-B Pro-Health Clinical Pro-Flex Toothbrush with Flexing Sides & 7 & $0.17 \pm 0.06$ & $<0.001$ \\
\hline Xlent Dental Activated Charcoal Bristle Toothbrush & 8 & $0.12 \pm 0.07$ & $<0.001$ \\
\hline Nimbus $^{\circledR}$ Microfine ${ }^{\circledR}$ Toothbrush Regular size & 9 & $0.10 \pm 0.04$ & $<0.001$ \\
\hline GUM Technique Deep Clean Toothbrush & 10 & $0.23 \pm 0.06$ & $<0.001$ \\
\hline Reach Advanced Design Soft & 11 & $0.16 \pm 0.07$ & $<0.001$ \\
\hline Colgate 360 Optic White Platinum soft & 12 & $0.18 \pm 0.09$ & $<0.001$ \\
\hline
\end{tabular}

${ }^{1}$ Wear index was presented as mean and standard deviation

${ }^{2} \mathrm{p}$ value is for the comparison between each toothbrush with the Sound Feelings SOFT Plain Toothbrush.

Table 2: Wear index mean, standard deviation and p-value for the toothbrushes in each group.

\begin{tabular}{|c|c|c|c|}
\hline Toothbrush Name & Group & Wear Rating $^{1}$ & P-value $^{2}$ \\
\hline Sound Feelings SOFT Plain Toothbrush & 1 & $0.57 \pm 0.61$ & \\
\hline Colgate ZigZag Black Soft Bristle Toothbrush & 2 & $0.91 \pm 0.70$ & 0.038 \\
\hline Oral-B 35 Soft Bristles 3D Vivid Toothbrush & 3 & $1.57 \pm 1.01$ & $<0.001$ \\
\hline Oral-B 40 Soft Bristles Complete Deep Clean Toothbrush & 4 & $1.60 \pm 0.77$ & $<0.001$ \\
\hline RADIUS Original Right Hand Toothbrush, Soft Bristles & 5 & $0.97 \pm 0.62$ & 0.008 \\
\hline Colgate Extra Clean Toothbrush & 6 & $1.23 \pm 0.77$ & $<0.001$ \\
\hline Oral-B Pro-Health Clinical Pro-Flex Toothbrush with Flexing Sides & 7 & $1.40 \pm 0.60$ & $<0.001$ \\
\hline Xlent Dental Activated Charcoal Bristle Toothbrush & 8 & $1.71 \pm 0.79$ & $<0.001$ \\
\hline Nimbus $^{\circledR}$ Microfine ${ }^{\circledR}$ Toothbrush Regular size & 9 & $1.26 \pm 0.44$ & $<0.001$ \\
\hline GUM Technique Deep Clean Toothbrush & 10 & $2.06 \pm 0.68$ & $<0.001$ \\
\hline Reach Advanced Design Soft & 11 & $0.74 \pm 0.61$ & 0.227 \\
\hline Colgate 360 Optic White Platinum soft & 12 & $1.31 \pm 0.72$ & $<0.001$ \\
\hline
\end{tabular}

${ }^{1}$ Wear rating was presented as mean and standard deviation.

${ }^{2} \mathrm{p}$ value is for the comparison between each toothbrush with the Sound Feelings SOFT Plain Toothbrush.

Table 3: Wear rating mean, standard deviation and p-value for the toothbrushes in each group.

\section{Discussion}

In this study, 11 commercial brushes were compared to the Sound Feelings SOFT Plain Toothbrush. The results showed that the Sound Feelings Soft Plain Toothbrush had the lowest wear among the twelve commercial toothbrushes tested. The Sound Feelings Soft Plain Toothbrush had less wear than the Colgate Zigzag Black Soft Bristle Toothbrush, Oral-B 35 Soft Bristles 3D Vivid Toothbrush, Oral-B 40 Soft Bristles Complete Deep Clean Toothbrush, RADIUS Original Right Hand Toothbrush, Colgate Extra Clean Toothbrush,
Oral-B Pro-Health Clinical Pro-Flex Toothbrush with Flexing Sides, Xlent Dental Activated Charcoal Bristle Toothbrush, Nimbus $\AA^{\circledR}$ Microfine ${ }^{\circledR}$ Toothbrush Regular size, GUM Technique Deep Clean Toothbrush, Reach Advanced Design Soft and Colgate 360 Optic White Platinum soft.

Within the confines of this study, we found that complex toothbrushes have the same, or more, wear than simple toothbrushes, with brushing technique/pattern, pressure, duration and external factors held constant. The main reason that these factors were held constant was because 


\section{Open Access Journal of Dental Sciences}

they have been shown to influence the majority of wear on toothbrushes [9]. Plain, flat bristle toothbrushes were seen to have less wear index than zig zag bristles, polishing cusp bristles, multilevel bristles, soft flat bristles, circular power bristles, pro-flex bristles, tapered charcoal-infused polyester bristles, multi-tufted/varying stiffness bristles, fine-tapered multilevel bristles, bi-level bristles and stain erasing cups with spiral bristles. This could be because the compact samelength bristles of the flat cut brush head tend to support each other under stress and prevent splaying [5]. This supports the results of this study with the Sound Feelings toothbrush having a plain flat brush head and having the least amount of wear.

Although there are not many other studies done like this, the results coincide with Rawls, et al. [5] that tested wear index and wear rating of groups of four different toothbrushes that had considerable design differences. The toothbrushes included were the Oral-B 15 TYNEX nylon 612 bristles, Oral-B 35 TYNEX nylon 612 bristles, Oral-B 40 TYNEX nylon 612 bristles, Oral-B P40 TYNEX nylon 612 bristles and AIM. There was a difference in tuft number, diameter and stiffness, bristle diameter and trim height and profile. The same measure of wear for subjective rating and the index calculation were used for this study. It was found that there was no difference between the different brush heads after simulating four weeks of use [5]. This supports the results and conclusions of this study and ensures that the results are reliable and within the normal limit.

The knowledge obtained from this study can be applied to the dental field for mechanical toothbrush users. Many patients, especially those in the elderly population, may prefer mechanical brushes over electric toothbrushes due to habit of what they have used for years, better control of the brush and/or no vibration "tickling" their gums [4]. It has been shown that the age of the toothbrush does not contribute to its efficacy, the level of wear does [10]. With the increase of wear, toothbrushes begin to have permanent curvatures, splay, which decreases their efficacy [11]. Both the wear and splay were examined in this study to accurately show patients if complex toothbrushes were able to withstand wear better than simple toothbrushes.

With greater toothbrush wear, there is a decrease in the amount of plaque removal, which causes the toothbrushes to be less effective. With a decrease in toothbrush effectiveness, the patient would be more likely to have caries and periodontal disease, which is the dental providers primary goal to prevent [6]. Dentists are able to tell their patients that in this bench study there is no difference in toothbrush wear between the "newest" or "latest" toothbrush with varying bristle material, head and/or angulation and a simple, flat bristle toothbrush, as long as they are brushing at least twice a day for two minutes, have the proper technique (Bass
Method) and do not apply excess pressure [3].

The limitations for this study were minimal, but since the same two dental students were cutting the toothbrushes (to fit in the simulator), running the brushes through the simulation, doing the wear ratings and wear index measurements, there could have been unintended, unconscious bias. However, each toothbrush was assigned a numerical number, or group, and after initial assignment, the names of the toothbrushes were never used again. There was no gain for either student to favor one toothbrush over another. For future experiments, it would be helpful to have two additional dental providers/students who are calibrated that are not involved in doing anything with the toothbrushes, other than doing wear ratings and measuring wear index to prevent any sort of bias. In addition, the use of the simulator and quadrant typodont in vitro may not completely mimic the brushing process of a real person. Therefore, a clinical study is necessary to conclusively prove the superior performance of the Sound Feelings Soft Plain Toothbrush compared to other complex toothbrushes regarding the wear.

\section{Conclusion}

The Sound Feelings Soft Plain Toothbrush had the lowest wear among the twelve commercial toothbrushes tested.

Financial Disclosure: This study was sponsored in part by Sound Feelings Inc.

\section{References}

1. Sanchez P, Everett B, Salamonson Y, Ajwani S, Bhole $S$, et al. (2017) Oral health and cardiovascular care: Perceptions of people with cardiovascular disease. PLoS One 12(7): e0181189.

2. Usha RS, Sathyanarayanan R (2009) Dental caries-A complete changeover (Part I). J Conserv Dent 12(2): 4654.

3. Mazhari F, Boskabady M, Moeintaghavi A, Habibi A (2018) The effect of toothbrushing and flossing sequence on interdental plaque reduction and fluoride retention: A randomized controlled clinical trial. J Periodontol 89(7): 824-832.

4. Petker W, Weik U, Margraf Stiksrud J, Deinzer R (2019) Oral cleanliness in daily users of powered vs. manual toothbrushes- a cross-sectional study. BMC Oral Health 19: 96.

5. Rawls HR, Mkwayi Tulloch NJ, Casella R, Cosgrove R (1989) The Measurement of Toothbrush Wear. J Dent Res 68(12): 1781-1785. 
Open Access Journal of Dental Sciences

6. Van Leeuwen M, Van der Weijden GA, Slot DE, Rosema M (2018) Toothbrush Wear in Relation to Tooth Brushing Effectiveness. Int J Dent Hyg 17(1): 77-84.

7. Gundavarapu KC, Ramachandra SS, Dicksit DD (2015) An investigation into toothbrush wear related to months of use among univeristy students. Can J Dent Hyg 49(2).

8. Suhasini J, Valiathan M (2020) Brushing Techniques. European Journal of Molecular \& Clinical Medicine 7(2): 6601-6611.

9. Pugh BR (1978) Toothbrush wear, brushing forces and cleaning performance. J Soc Cosmet Chem 29(7): 423-431.

10. Rosema NA, Hennequin Hoenderdos NL, Versteeg PA, van Palenstein Helderman WH, van der Velden $\mathrm{U}$, et al. (2013) Plaque-removing efficacy of new and used manual toothbrushes--a professional brushing study. Int J Dent Hyg 11(4): 237-243.

11. Schneider P, Musselman R, Sarkar NK (1995) Effect of a clamp on toothbrush bristle deterioration. J Clin Dent 6(4): 198-201. 